\title{
Thermodynamic and Kinetic Study of the Intrinsic Adsorption Capacity of Graphene Oxide for Malachite Green Removal from Aqueous Solution
}

\author{
PRAWIT NUENGMATCHA, RATANA MAHACHAI and SAKSIT CHANTHAI* \\ Department of Chemistry and Center of Excellence for Innovation in Chemistry, \\ Faculty of Science, Khon Kaen University, Khon Kaen 40002, Thailand. \\ ${ }^{*}$ Corresponding author E-mail: sakcha2@kku.ac.th \\ http://dx.doi.org/10.13005/ojc/300403
}

(Received: August 14, 2014; Accepted: September 26, 2014)

\begin{abstract}
Graphene oxide (GO) was produced from bare graphite (BGP) material and was used as an intrinsic adsorbent for the removal of malachite green (MG) from aqueous solution. In an optimization study, the effects of the initial concentration of $\mathrm{MG}$, solution $\mathrm{pH}$, adsorbent dosage, contact time and ionic strength were investigated in detail. The water-soluble dye was analyzed at a maximum wavelength of $618 \mathrm{~nm}$. The optimum conditions for MG removal from aqueous solution included a $300 \mathrm{mg} / \mathrm{L}$ initial concentration with $0.02 \mathrm{mg}$ adsorbent at $\mathrm{pH} 5.1$, and complete adsorption equilibrium was reached within $40 \mathrm{~min}$. The maximum adsorption capacity of GO for MG was $384.62 \mathrm{mg} / \mathrm{g}$, dramatically higher (over 10 times) than that of BGP $(28.73 \mathrm{mg} / \mathrm{g})$. The adsorption process followed pseudo-second-order kinetics. Thermodynamic data demonstrated that dye adsorption onto the GO surface was mainly an exothermic spontaneous reaction. The remarkably different adsorption isotherms for GO and BGP fit well with the Langmuir and Freundlich models, respectively. It is therefore evident that the prepared GO can be used as a highly effective adsorbent for this toxic dye.
\end{abstract}

Key words:Graphene oxide; Malachite green; Adsorption isotherm; Thermodynamic;Kinetic

\section{INTRODUCTION}

Currently, many industries, including paper production, textiles, leather tanning, plastics, hair coloring and food technology, use synthetic dyes to color their final products. Malachite green (MG) is one of the most commonly used dyes for cotton, leather, silk, paper and printing inks ${ }^{1}$, and it can also be used as an anti-parasitic and antifungal agent in aquariums ${ }^{2}$. However, malachite green and its major metabolite, leucomalachite green, bothhave mutagenic, carcinogenic, genotoxic and teratogenic effects ${ }^{3-4}$. Whenever environmental contamination occurs, they bio-accumulatein aquatic life such as fish, crab, shrimp, mollusks and other animals ${ }^{5-6}$ and cause detrimental effects in 
liver, gall, kidney, intestine, gonad and pituitary gonadotrophic cells. ${ }^{7}$ Ultimately, human beings in the affected food chain risk becoming sick. Therefore, it is necessary to remove these dye contaminants from wastewater before release into the environment to protect both the environment and humans.

There are several techniques for the removal of malachite green from wastewater, such as photocatalysis ${ }^{8-10}$, nanofibermembrane ${ }^{11}$, precipitation ${ }^{12}$, electrocoagulation, flotation, chemical oxidation, filtration, ozonation ${ }^{13}$, microbial degradation, ion exchange, and adsorption ${ }^{14-19}$. Among those techniques, adsorption is the most promising process for the removal of dyes from wastewater. This method relies on interactions between adsorbent and adsorbate. Thus, a key factor in the adsorption process is the selective adsorbent with its intrinsic functional groups. Several adsorbents that have been studied for removal of malachite green include eggshells ${ }^{2}$, clay ${ }^{3}$, rice husk, bentonite,zeolite,sawdust,rice straw,oil palm trunk fiber,degreased coffee beans,treated ginger waste, hen feathers, chitin hydrogel,chitosan beads, silica gel,acid-activated sintering process red mud, water-soluble melamine/maleic anhydride sorbent ${ }^{20}$ ${ }^{33}$, activated carbonand other carbon-based materials ${ }^{34-40}$. However, because these adsorbents are low in either efficiency or adsorption capacity,new adsorbents have recently been developed that possess high capacity, larger specific surface area and high selectivity.

Recently, graphene oxide (GO) was demonstrated to be a candidate carbon-based adsorbent due to having of non-specific functional groups (carbonyl, hydroxyl and epoxide) on its surface, providing anchor sites for both dye and metal ion complexation ${ }^{41-44}$. The abundance of functional groups on its surface gives $\mathrm{GO}$ adsorption capability for dyes such as methylene blue,congo red,sulfamethoxazole, ciprofloxacin, acridine orange, methyl orange, methyl violet, rhodamine $B$ and orange $\mathrm{G}^{45-51}$. However, the removal of malachite green from aqueous solutionby using graphene oxide has not yet been reported inthe literature.

In this study,GO was chemically produced from graphitic materialand used to remove malachite green from aqueous solution. In a batch adsorption study, the potential of GO for use as an adsorbentin malachite green removalwas assessed via comparison withbare graphite.Both Langmuir and Freundlich isotherms, adsorption kinetics and thermodynamic parameters were investigatedin detailto determine theadsorption capacity for malachite green removal from aqueous solution.

\section{MATERIALS AND METHODS}

Sodium nitrate $\left(\mathrm{NaNO}_{3}\right)$, sulfuric acid $\left(\mathrm{H}_{2} \mathrm{SO}_{4}, 98 \%\right)$, hydrogen peroxide $\left(\mathrm{H}_{2} \mathrm{O}_{2}, 30 \%\right)$, and ethanol $\left(\mathrm{C}_{2} \mathrm{H}_{5} \mathrm{OH}\right)$ were purchased from Ajax FineChem Pty Ltd. Potassium permanganate $\left(\mathrm{KMnO}_{4}\right)$, synthetic graphite powder $(<20 \mu \mathrm{m})$ and malachite green oxalate $\left(\left[\mathrm{C}_{23} \mathrm{H}_{25} \mathrm{~N}_{2}\right) \cdot\left(\mathrm{C}_{2} \mathrm{HO}_{4}\right)\right]_{2}$. $\mathrm{C}_{2} \mathrm{H}_{2} \mathrm{O}_{4}$ ) were received and used without further purification.Each of their working solutions was prepared by diluting standard stocksolutions from Carlo Erbaand Sigma-Aldrich. All chemicals used were reagent grade.Malachite green in the supernatant solution was determined using anultraviolet and visible spectrophotometer (Agilent 8453, Germany) at a wavelength of $618 \mathrm{~nm}$.

\section{Preparation of graphene oxide}

Graphene oxide was prepared from graphite powder by using conditions optimized in our previous work ${ }^{52}$ with the modified Hummers' method $^{53}$. Briefly, $3.0 \mathrm{~g}$ of graphite powder was added to cold $\left(0^{\circ} \mathrm{C}\right) 300 \mathrm{~mL}$ of $98 \% \mathrm{H}_{2} \mathrm{SO}_{4}$ and stirred for $30 \mathrm{~min}$. Then, $3.0 \mathrm{~g}$ of $\mathrm{NaNO}_{3}$ was added portion-wise to the mixture and stirred a further 30 $\min$. Subsequently, solid powder of $\mathrm{KMnO}_{4}(4.5 \%$, w/v) was added to the mixture, which was always kept below $10^{\circ} \mathrm{C}$ in an ice bath. After stirring for 30 min, $200 \mathrm{~mL}$ of deionized water was then slowly added to the mixture and stirred again for $30 \mathrm{~min}$. After that, it was heated to $80^{\circ} \mathrm{C}$ for $6 \mathrm{~h}$ and $40 \mathrm{~mL}$ of $30 \% \mathrm{H}_{2} \mathrm{O}_{2}$ was slowly added. The mixture solution was centrifuged and washed several times with deionized water until the $\mathrm{pH}$ of the filtrate reached neutral. The lyophilized precipitates were subsequently obtained

\section{Determination of $\mathrm{pH}_{\mathrm{pzc}}$}

$\mathrm{pH}$ at the point of zero charge $\left(\mathrm{pH}_{\mathrm{pzc}}\right)$ for the $\mathrm{GO}$ adsorbent in a solid to solution ratio of 1:250 was determined bythe batch equilibration 
technique ${ }^{54}$.Sodium chloride solution $(0.1 \mathrm{~mol} /$ $\mathrm{LNaCl}$ ) was used as an inert electrolyte. Initial $\mathrm{pH}$ values $\left(\mathrm{pH}_{\text {initial }}\right)$ of the $\mathrm{NaCl}$ solutions were adjusted from 1 to 12 by addition of $0.1 \mathrm{~mol} / \mathrm{LHCl}$ or $\mathrm{NaOH}$. $\mathrm{GO}$ adsorbent $(0.1 \mathrm{~g})$ was added into $25 \mathrm{~mL}$ of 0.1 $\mathrm{mol} / \mathrm{LNaCl}$ solution. The suspension mixture $(1: 250)$ was allowed to equilibrate for $24 \mathrm{~h}$ in a shaker maintained at room temperature $\left(30^{\circ} \mathrm{C}\right)$. Then, the suspension solution was filtered and the $\mathrm{pH}$ values $\left(\mathrm{pH}_{\text {final }}\right)$ were measured once.

\section{Adsorption experiments}

For batch adsorption of malachite green, the adsorbent $(0.02 \mathrm{~g})$ was accurately weighed into a $125 \mathrm{~mL}$ conical flask. Then, $25 \mathrm{mLof}$ the dye solution $(300 \mathrm{mg} / \mathrm{L})$ was added, the $\mathrm{pH}$ of the solution was adjusted and it was shaken by an orbital shaker at approximately $200 \mathrm{rpm}$ at ambient temperature $\left(30^{\circ} \mathrm{C}\right)$. For optimum batch adsorption conditions, various experimental parameters were studied including $\mathrm{pH}$ range (2-8), initial concentration of dye, temperature and contact time .After a period of shaking, the adsorbent was separated from the solutionby centrifugation for 5 min and the supernatant solution was determined spectrophotometrically.

All experiments were conducted in triplicate under the same conditions. The adsorption capacity $\left(q_{e}, \mathrm{mg} / \mathrm{g}\right)$ of the dyeat an equilibrium state was determined as follows:

$$
q_{e}=\frac{V\left(C_{0}-C_{e}\right)}{m}
$$

Table 1: Thermodynamic parameters of MG adsorption onto GO at different temperatures in Kelvin

\begin{tabular}{|c|c|c|c|c|c|c|}
\hline \multirow{2}{*}{$\begin{array}{l}\Delta \mathrm{H}^{\circ} \\
(\mathrm{kJ} / \mathrm{mol})\end{array}$} & \multirow{2}{*}{$\begin{array}{c}\Delta S^{\circ} \\
(\mathrm{kJ} / \mathrm{mol} . \mathrm{K})\end{array}$} & \multicolumn{4}{|c|}{$\Delta \mathrm{G}^{\circ}(\mathrm{kJ} / \mathrm{mol})$} & \multirow[t]{2}{*}{$\mathbf{R}^{2}$} \\
\hline & & $303 \mathrm{~K}$ & $313 \mathrm{~K}$ & $323 \mathrm{~K}$ & $333 \mathrm{~K}$ & \\
\hline-49.42 & -134.89 & -26.00 & -24.94 & -24.75 & -23.47 & 0.9835 \\
\hline
\end{tabular}

Table 2: Kinetic parameters of GO adsorbent at a temperature of $303 \mathrm{~K}$

\begin{tabular}{|c|c|c|c|c|c|c|}
\hline \multirow{2}{*}{$\frac{q_{e, \exp }(\mathbf{m g} / \mathbf{g})}{296.80}$} & \multicolumn{2}{|c|}{ First order } & \multicolumn{2}{|c|}{ Pseudo-second order } & \multicolumn{2}{|c|}{ Intraparticle diffusion } \\
\hline & $q_{1}(m g / g)$ & 163.93 & $\mathrm{q}_{2}(\mathrm{mg} / \mathrm{g})$ & 312.50 & $\mathrm{k}_{\mathrm{p}}\left(\mathrm{mg} / \mathrm{g} \cdot \mathrm{min}^{1 / 2}\right)$ & 26.923 \\
\hline & $\mathrm{k}_{1}(\min )$ & 2.1967 & $\mathrm{k}_{2}(\mathrm{~g} / \mathrm{mg} \cdot \min )$ & 0.0031 & C $(\mathrm{mg} / \mathrm{g})$ & 128.38 \\
\hline & $\mathrm{R}^{2}$ & 0.7615 & $\mathrm{R}^{2}$ & 0.9995 & $\mathrm{R}^{2}$ & 0.9678 \\
\hline
\end{tabular}

$\mathrm{L})$ of the dyein solution, $C$ is the dye concentration $(\mathrm{mg} / \mathrm{L})$ at the equilibrium state, $V$ is the volume $(\mathrm{L})$ of the solution, andmisthe mass ( $\mathrm{g}$ ) of the adsorbent. Langmuir and Freundlichadsorption models were used to describe the equilibriumnature of dyeadsorption onto the GOand compare it with a BGP adsorbent.

\section{RESULTS AND DISCUSSION}

\section{Characterization of graphene oxide}

Figure1clearly demonstrates thep $\mathrm{H}_{\mathrm{pzc}}$ of the obtained graphene oxide. The plateau corresponds to a plot of final pHvalue of the suspension $\left(\mathrm{pH}_{\text {final }}\right)$ against the initial value $\left(\mathrm{pH}_{\text {initial }}\right)$ to give thepH $\mathrm{H}_{\mathrm{pzc}}$ value. The presence of the plateau indicates that the material exhibits amphoteric properties and acts as a bufferin this range. The plateau of $\mathrm{pH}_{\text {initial }}$ minus $\mathrm{pH}_{\text {final }}$ corresponds to the $\mathrm{pH}$ range where the buffering capacity of the $\mathrm{GO}$ occurs, i.e., where for all $\mathrm{pH}$ values, in this range the $\mathrm{pH}_{\text {final }}$ is almost the same and corresponds to $\mathrm{pH}_{\mathrm{pzc}}$. It is evident that the GO possesses a buffering effect over a wide $\mathrm{pH}$ range, from 4 to 9 . Thus, for all values of $\mathrm{pH}_{\text {initial }}, \mathrm{pH}_{\text {final }}$ is the same and equal to $\mathrm{pH}_{\mathrm{pzc}}$. One may notice that at $\mathrm{pH} 3 \mathrm{GO}$ tends to act as a buffer, but the buffering effect is incomplete and the $\mathrm{pH}_{\text {final }}$ values remain under the plateau. The $\mathrm{pH}_{\mathrm{pzc}}$ of $\mathrm{GO}$ was observed to be $\mathrm{pH}$ 4.1. Similar observations were reported for2- or 3-layered and few-layered graphene oxide with $\mathrm{pH}_{\mathrm{pzc}} \mathrm{s}$ of 4.1 and 3.8 , respectively ${ }^{55}$. Its $\mathrm{pH}_{\mathrm{pzc}}$ suggests that the surface of $\mathrm{GO}$ should be predominantly positive at $\mathrm{pH}$ 
values lower than 4.1 and negative at $\mathrm{pH}$ values higher than 4.1. The surface charge density of the material should decrease the $\mathrm{pH}$ of the solution approaches $\mathrm{pH}_{\mathrm{pzc}}$ and increase as it deviates from $\mathrm{pH}_{\mathrm{pzc}}$.

\section{Adsorption of malachite green dye Effect of initial concentration}

The effect of the initial concentration of malachite green (MG)is a very important parameter for adsorption studies because it can overcome all MG mass transfer restrictions between the aqueous and solid phases. Figure 2 shows plots of the equilibrium adsorption capacity of $\mathrm{GO}$ and the percentage removal of $M G$ versus the initial concentration of MG. It is evident that the equilibrium adsorption capacity increases with increasing initial dye concentration, indicating that a higher initial concentration of MG can enhance the adsorption process, although the percentage removal of MG decreases with an increase in the initial concentration. The maximum adsorption capacity of the GO adsorbent at MG concentration of 300 $\mathrm{mg} / \mathrm{L}$ is $233.40 \mathrm{mg} / \mathrm{g}$. The increasing uptake capacity of thea dsorbent with increasing MG concentration may be due to higher collision probability between MG ions and adsorbent particles. Moreover, variation in the extent of adsorption may also be because at the initial stage all active sites of the adsorbent surfaceare vacant and the dye concentration gradient is relatively high. Similar trends have been reported in the literature for the removal of MG using othe radsorbents such as Araucaria cookiiBark ${ }^{7}$, sawdust $^{23}$, rice husk activated carbon $^{35}$ and clayey soil ${ }^{56}$.

\section{Effect of $\mathrm{pH}$}

The $\mathrm{pH}$ of an aqueous solution is generally said to be a very critical parameter affecting the adsorption process due to the functional groups of both the adsorbed molecules and the adsorbent particles. Hydrogen ions $\left(\mathrm{H}^{+}\right)$in the solution are directly involved in the adsorption process at the active sites of the adsorbent. The influence of initial $\mathrm{pH}$ on adsorption efficiency was evaluated in terms of adsorption capacity.

Table 3: Results and parameters associated with the Langmuir and Freundlich models

\begin{tabular}{lcccccccc}
\hline \multirow{2}{*}{ Adsorbent } & \multicolumn{3}{c}{ Langmuir Isotherm } & & \multicolumn{3}{c}{ Freundlich Isotherm } \\
\cline { 2 - 3 } & $\mathbf{q}_{\max (\mathrm{mg} / \mathrm{g})}$ & $\mathrm{K}_{\mathrm{L}}$ & $\mathbf{R}^{2}$ & & $\mathrm{~K}_{\mathrm{F}}$ & $\mathbf{1} \mathbf{n}$ & $\mathbf{R}^{2}$ \\
\hline BGP & 28.73 & 0.026 & 0.9610 & & 1.34 & 0.6290 & 0.9745 \\
GO & 384.62 & 0.264 & 0.9993 & & 68.30 & 0.6729 & 0.9337 \\
\hline
\end{tabular}

Table 4: Comparison of adsorption capacities of various activated carbon and carbon-based adsorbents for MG

\begin{tabular}{lll}
\hline Adsorbent & $\mathbf{q}_{\mathrm{e}}(\mathbf{m g} / \mathbf{g})$ & References \\
\hline Activated carbon from epicarp of $R$. communis & 27.78 & {$[39]$} \\
Palm flower activated carbon & 48.48 & {$[38]$} \\
Rice husk activated carbon & 49.62 & {$[35]$} \\
Activated carbon loaded with Tin oxide nanoparticles & 142.87 & {$[34]$} \\
Groundnut shell based powdered activated carbon & 222.22 & {$[55]$} \\
Rubber seed coat based activated carbon & 227.27 & {$[54]$} \\
Ordered mesoporous carbons & $248.8-354.5$ & {$[36]$} \\
Activated carbon prepared from bamboo & 263.58 & {$[18]$} \\
Rambutan peel-based activated carbon & 329.49 & {$[37]$} \\
Bare graphite & 28.73 & This work \\
Graphene oxide & 384.62 & This work \\
\hline
\end{tabular}




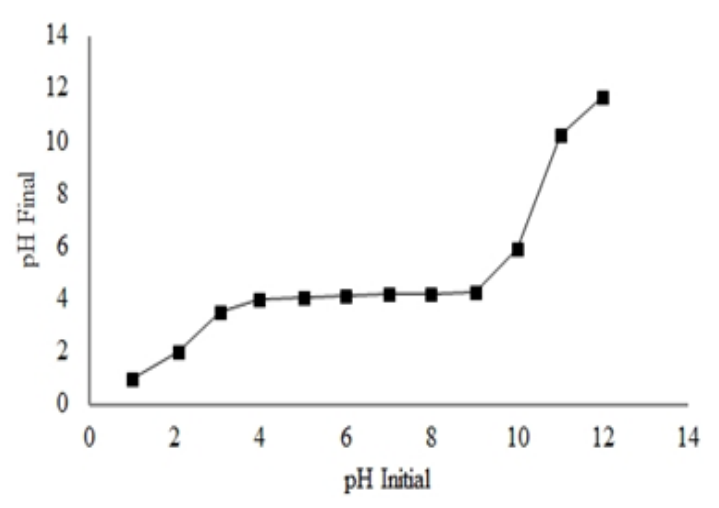

Fig. 1: Plot of final solution $\mathrm{pH}\left(\mathrm{pH}_{\text {final }}\right)$ versus initial $\mathrm{pH}\left(\mathrm{pH}_{\text {initial }}\right)$ for solid to solution ratio 1:250. Time of equilibration $24 \mathrm{~h}$. Background electrolyte $0.1 \mathrm{~mol} / \mathrm{L} \mathrm{NaCl}$.

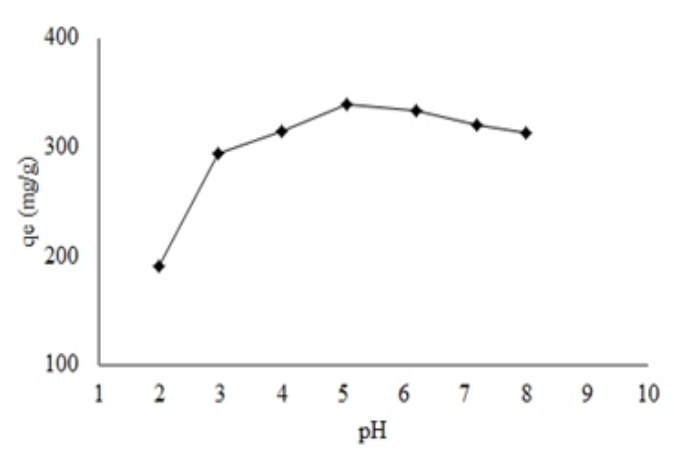

Fig. 3: Effect of pH on adsorption of MG using $\mathrm{GO}$ as adsorbent

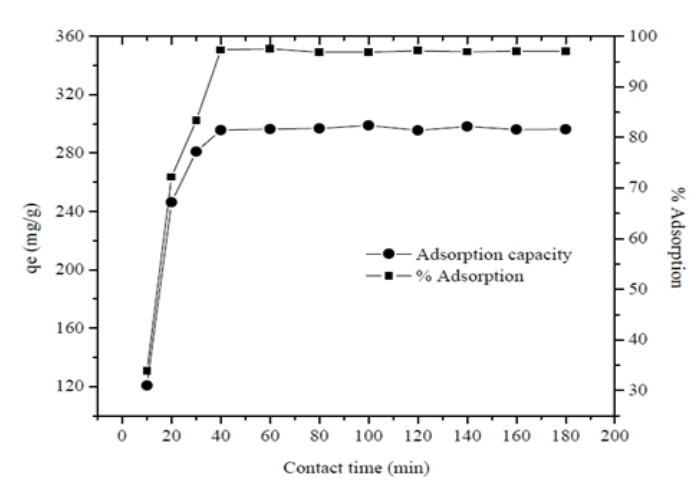

Fig. 5: Effect of contact time on adsorption of MG using GO as adsorbent

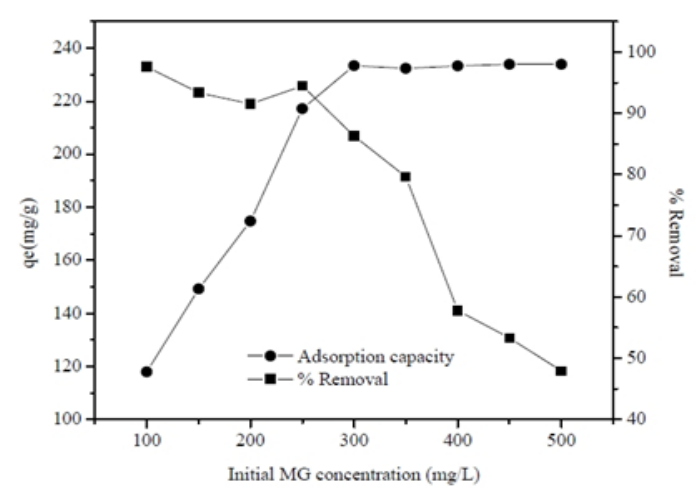

Fig. 2: Effect of initial concentration on MG adsorption using $\mathrm{GO}$ as the adsorbent

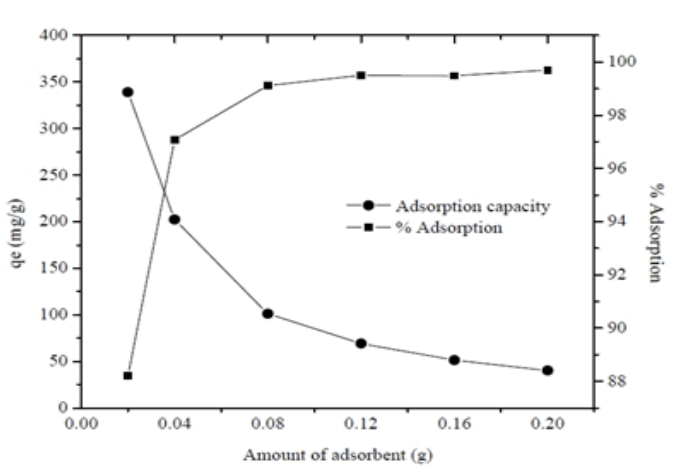

Fig. 4: Effect of adsorbent dosage on adsorption of MG using GO as adsorbent

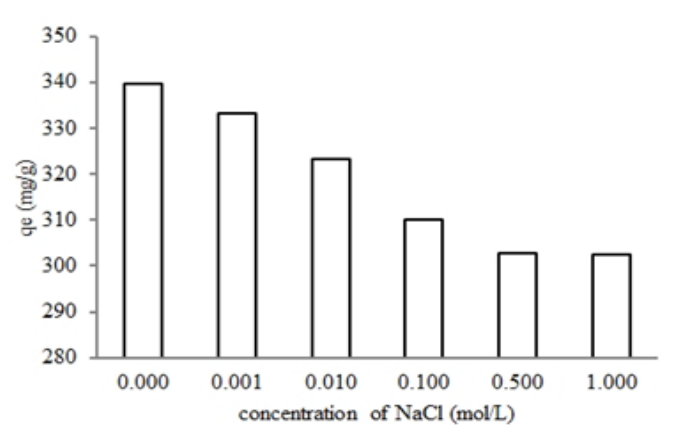

Fig. 6: Effect of ionic strength on adsorption of MG using GO as adsorbent 
Figure 3shows the MG adsorption capacity over the $\mathrm{pH}$ range of 2-8. It was observed that the adsorption of MG increases with increasing solution $\mathrm{pH}$. At pH 2, the extent of MG adsorption was 190.53 $\mathrm{mg} / \mathrm{g}$. The adsorption capacity increased from $\mathrm{pH} 2$ to 5 , reached its maximum value at $\mathrm{pH} 5.1$, and then declined as the pHof the solution increased further. The maximum adsorption capacity of GO (338.22 $\mathrm{mg} / \mathrm{g}$ ) occurred at $\mathrm{pH}$ 5.1. As reported previously, the $\mathrm{pH}_{\mathrm{pzc}}$ of $\mathrm{GO}$ was 4.1. At lower solution $\mathrm{pH}$, the adsorption capacity of $\mathrm{GO}$ is lower due to the competition between $\mathrm{H}^{+}$and $\mathrm{MG}$ ions anchored at the adsorption sites. In addition, in an acidic solution, the adsorbent surface becomes positively charge and does not favor the uptake of MG ions. On the other hand, at higher $\mathrm{pH}$ values, the surface of the adsorbent becomes negatively charged and favors the uptake of the dye. However, the adsorption capacity of GO decreased from $\mathrm{pH} 5$ to 8 , which may be due to the ionization constant $(\mathrm{pK}=6.90)$ of the dye making it $100 \%$ ionized at $\mathrm{pH} 4,50 \%$ at $\mathrm{pH}$ $6.9,25 \%$ at 7.4 and $0 \%$ at $\mathrm{pH} 10.1^{4}$. In this study, $\mathrm{pH}$ 5.1 was chosen as the optimal experiment condition because this $\mathrm{pH}$ could accommodate both the activity of the functional groups on the GO surface (negatively charged) and also strong chemical ionization of MG (positively charged). A similar trend was observed for the biosorption of MG on Araucaria cookii Bark?

\section{Effect of adsorbent dosage}

Because an adsorbent dosage assessment can providei nformation about an effective adsorbent to use and the ability of MG to be adsorbed with a minimum dosage, it is beneficial from an economical point of view. The effect of the adsorbent dosage on dye adsorption by $\mathrm{GO}$ is shown in Fig. 4.Percentage (\%) MG adsorption was plotted as a function of the adsorbent dosagein the range of 0.02-0.2 g. It is clear that the adsorption percentage of the GO sorbent increases with the an increase of the adsorbent dosage. This is because the increasing dosage leads to an increase in the number of active sites available in the adsorbent, resulting in an increased amount of adsorbed MG ions. On the other hand, it was found that the adsorption capacity is high at low dosages and decreases at higher dosages. This may be attributable to the decrease in total adsorption surface area available to $M G$ resulted from an overlapping or an aggregation of the adsorption sites $^{1}$. In this study, $0.02 \mathrm{~g}$ of GO was chosen due its highest adsorption capacity.

\section{Effect of contact time}

The effect of contact time on the adsorption capacity of GO for malachite green $(300 \mathrm{mg} / \mathrm{L})$ was evaluated. Fig. 5 clearly shows that the rate of adsorption increases at the initial period of contact time and decreases gradually with time until the adsorption reaches an equilibrium condition. The equilibrium state was established within $40 \mathrm{~min}$. At the initial stage (first $30 \mathrm{~min}$ ), the MG adsorption rate may be explained by an increased availability in the number of active sites on the surface of the GO adsorbent. The adsorption of MG ontothe adsorbent drastically increases and is normally controlled by the diffusion process from the bulk solution to the surface of the adsorbent. In the final stage, the adsorption of MG is likely an attachment controlled process due to fewer available sorption sites. Therefore, further studies were conducted using $40 \mathrm{~min}$ as a suitable contact time for dye adsorption.

\section{Effect of ionic strength}

The effect of ionic strength on the adsorption capacity of graphene oxide $(0.02 \mathrm{mg})$ for malachite green $(300 \mathrm{mg} / \mathrm{L})$ at $303 \mathrm{~K}$ for $40 \mathrm{~min}$ was assessed. From Fig. 6, it is evident that dye adsorption decreased with increasing $\mathrm{NaCl}$ concentration $(0.001-0.100 \mathrm{~mol} / \mathrm{L})$ and remained constant with an excess amount of sodium salt $(>0.500 \mathrm{~mol} / \mathrm{L})$ in the solution. A similar trend was found in $M G$ adsorption using activated carbon obtained from tea leaves ${ }^{1}$. This result corresponds with the theoretical aspect that when the electrostatic forces between the adsorption surface and adsorbate ions are attractive, an increase in the ionic strength will decrease the adsorption capacity.

\section{Thermodynamic study of dye adsorption}

To study the effect of temperature on the adsorption of MG onto GO, the Gibbs free energy change $\left(\Delta G^{\circ}\right)$, entropy change $\left(\Delta S^{\circ}\right)$ and enthalpy change $\left(\Delta \mathrm{H}^{\circ}\right)$ were estimated by applying thermodynamic equations (2) to (4).

$$
\Delta G^{\circ}=-R T \ln K_{d}
$$


Where $R$ is the gas constant $(8.314 \mathrm{~J} /$ molK), $T$ is absolute temperature in $\mathrm{K}$ and $K_{d}$ is the equilibrium constant. The $K_{d}$ was calculated by using the following equation:

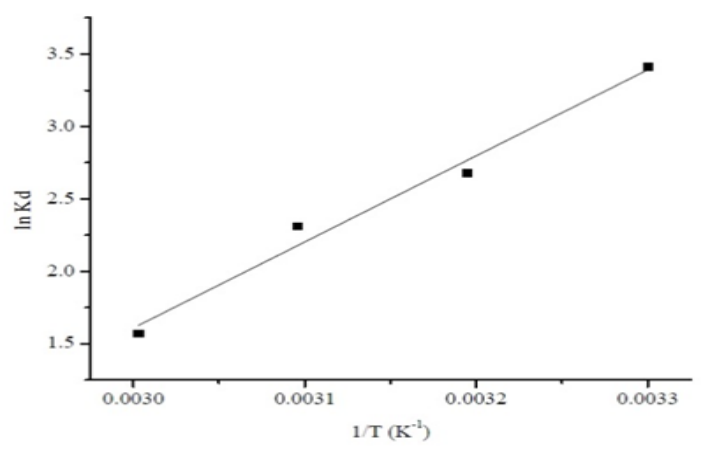

Fig. 7: Plot of In $K_{d}$ versus 1/T for MG adsorption onto $\mathrm{GO}$ at different temperatures

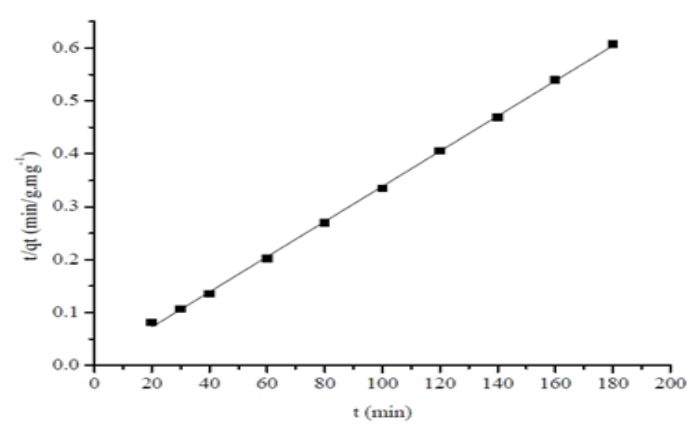

Fig. 9: The pseudo-second-order kinetic model of MG adsorption onto $\mathrm{GO}$ at a temperature of $303 \mathrm{~K}$

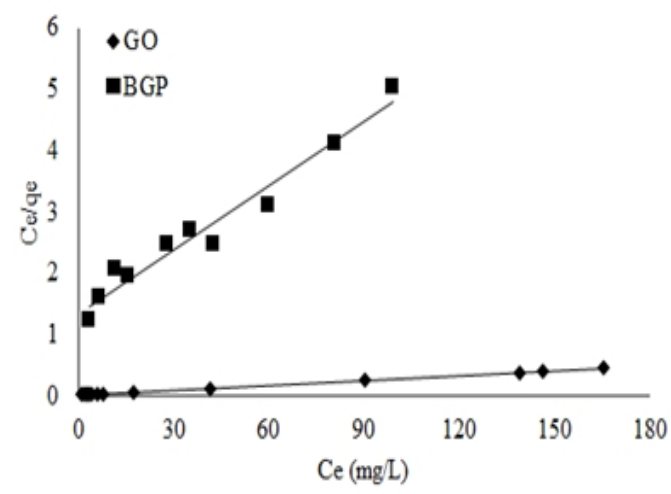

Fig. 11: The Langmuir adsorption plots for MG adsorption onto $G O$ and BGP at a temperature of $303 \mathrm{~K}$

$$
K_{d}=\frac{q_{e}}{C_{e}}
$$

Where $q_{e}$ is amount of malachite green $(\mathrm{mg})$ adsorbed per gram of $\mathrm{GO}$ at equilibrium, $\mathrm{C}_{\mathrm{e}}$ is the

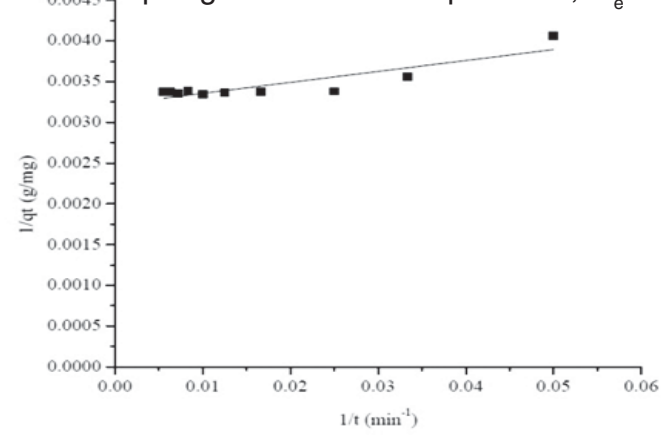

Fig. 8: First-order kinetic model of MG adsorption onto $\mathrm{GO}$ at a temperature of $303 \mathrm{~K}$

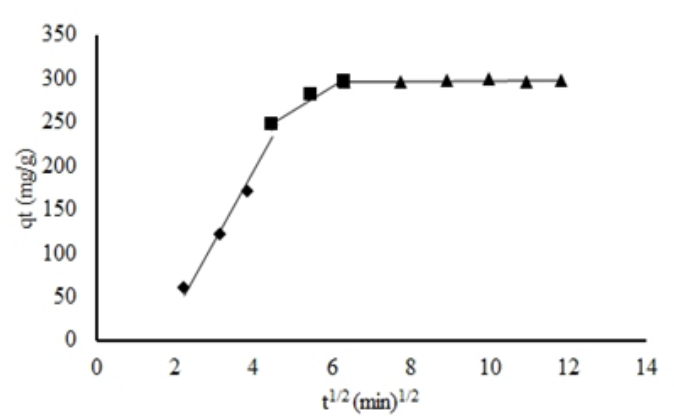

Fig. 10: Intra-particle diffusion kinetic model of MG adsorption onto $\mathrm{GO}$ at a temperature of $303 \mathrm{~K}$

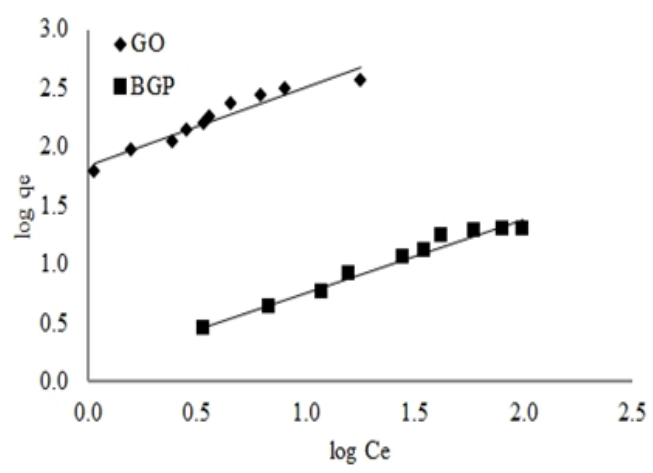

Fig. 12: The Freundlich adsorption plots for MG adsorption onto GO and BGP at a temperature of $303 \mathrm{~K}$ 
equilibrium concentration $(\mathrm{mg} / \mathrm{L})$ of malachite green in solution and $K_{d}$ is the distribution coefficient for sorption.

$$
\ln K_{d}=-\frac{\Delta H^{\circ}}{R T}+\frac{\Delta S^{\circ}}{R}
$$

The values of $\Delta \mathrm{S}^{\circ}$ and $\Delta \mathrm{H}^{\circ}$ can be calculated from the slope and the intercept of the

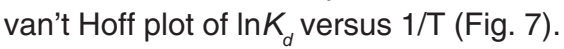

From Table 1, under the steady-state reaction condition, $\Delta \mathrm{G}^{\circ}$ is in the range from -26.00 to $-23.47 \mathrm{~kJ} / \mathrm{mol}$ and $\Delta \mathrm{H}^{\circ}$ and $\Delta \mathrm{S}^{\circ}$ are found to be$49.42 \mathrm{~kJ} / \mathrm{mol}$ and $-134.89 \mathrm{~kJ} / \mathrm{mol}$.K, respectively. The negative value of $\Delta \mathrm{G}$ o for all temperatures indicates that the adsorption is a spontaneous process ${ }^{38}$. One can note that $\Delta \mathrm{G}^{\circ}$ values above -20 $\mathrm{kJ} /$ molare an indicator of physisorption, while values more negative than $-40 \mathrm{~kJ} / \mathrm{mol}$ indicate chemisorption. When $\Delta \mathrm{G}^{\circ}$ is in the range between 20 and $-40 \mathrm{~kJ} / \mathrm{mol}$, both physisorption and chemisorption occur ${ }^{1}$.In this study, the $\Delta \mathrm{G}^{\circ}$ valuesare in between -20 and $-40 \mathrm{~kJ} / \mathrm{mol}$, indicating that the sorption process can be explained by taking both physisorption and chemisorption into consideration. The negative value of $\Delta \mathrm{S}^{\circ}$ indicates a tendency to lower disorder at the solid-solution interface during adsorption ${ }^{57}$.In addition, the negative value of $\Delta \mathrm{H}^{\circ}$ indicates that dye adsorption using $\mathrm{GO}$ is exothermic nature. At high temperature the thickness of the boundary layer decreases due to the increased tendency of the dye molecules to escape from the adsorbent surface to the solution, which results in a decrease in the adsorption capacity as the temperatureincreases ${ }^{56}$.

\section{Kinetic study of dye adsorption}

The nature of the adsorption process depends on either physical or chemical characteristics of the adsorbent. Three kinetic models including a first-order kinetic model, a pseudo-second-order kinetic model and an intraparticle diffusion kinetic model are used to examine the mechanism of the adsorption process.

The first order rate equation is one of the most widely used for the adsorption of solute from a solution, which is given in the following Eq. (5).

$$
\frac{1}{q_{t}}=\frac{k_{1}}{q_{1}} \frac{1}{t}+\frac{1}{q_{t}}
$$

Where $q_{1}$ and $q_{t}$ are the amounts of MG adsorbed onto adsorbent at equilibrium $(\mathrm{mg} / \mathrm{g})$ and at various times $t$, respectively, and $k_{1}$ is the rate constant $\left(\mathrm{min}^{-1}\right)$ of the first order model for the adsorption process. The values of and are calculated from the slope and intercept of the plot(Fig. 8) of 1/ $q_{t}$ versus $1 / t$.

The pseudo-second order kinetic model is expressed by Eq.(6)

$$
\frac{t}{q_{t}}=\frac{1}{k_{2} q_{2}^{2}}+\frac{1}{q_{t}}
$$

Where $\mathrm{q}_{2}$ is the maximum adsorption capacity $(\mathrm{mg} / \mathrm{g})$ for pseudo-second-order adsorption, $q_{t}$ is the amount of MG adsorbed at equilibrium $(\mathrm{mg} / \mathrm{g})$ at time $t(\mathrm{~min})$ and $\mathrm{k}_{2}$ is the rate constant of the pseudo-second-order adsorption ( $\mathrm{g} / \mathrm{mg} \mathrm{min})$. The values of and were calculated from the slope and intercept of the plot (Fig. 9) of t/ $\mathrm{q}_{\mathrm{t}}$ versus $t$.

Because the first order and pseudosecond order kinetic models cannot be used to identify the diffusion mechanism, an intra-particle diffusion model was also used. The structure of the solid and its interaction with diffusion controls the rate of transport. Intra-particle diffusion is a transport process involving the movements of species from bulk solution to a solid phase. During well-stirred batch adsorption, the intra-particle diffusion model has been used to explain the adsorption mechanism occurring on a porous adsorbent. A plot of the amount of $M G$ adsorbed at equilibration at time $t$ and $t^{1 / 2}$ provides the intra-particle diffusion rate constant (the slope of the plot). The intra-particle diffusion model is expressed by Eq.(7).

$$
q_{t}=k_{p} t^{\frac{1}{2}}+C
$$


Where qis the amount of MG adsorbed at equilibrium $(\mathrm{mg} / \mathrm{g})$ at time $\mathrm{t}, \mathrm{C}$ is the intercept and $\mathrm{k}_{\mathrm{p}}$ is the intra-particle diffusion rate constant $\mathrm{mg} / \mathrm{g}$ $\left.\min ^{1 / 2}\right)$. The values of and $\mathrm{C}$ were calculated from the slope and intercept of the plot of versus $t^{1 / 2}$. The value of $\mathrm{C}$ is the intra-particle diffusion constant, which is directly proportional to the boundary layer thickness.

The kinetic parameters for the dye adsorption of $\mathrm{GO}$ at $303 \mathrm{~K}$ were calculated from Eqs. (5)-(7) as shown in Table 2. It was found that the $q_{2}$ value of $\mathrm{GO}$ sorbent is $312.50 \mathrm{mg} / \mathrm{g}$ and the linear correlation coefficient $\left(R^{2}\right)$ is up to 0.9995 . Moreover,the calculated $(296.80 \mathrm{mg} / \mathrm{g})$ and experimental $\left(q_{e}, 312.50 \mathrm{mg} / \mathrm{g}\right)$ values are close to each other. Therefore, this dye adsorption fits well with the pseudo-second-order kinetic model.

Figure 10 shows the intra-particle diffusion for MG adsorption using GO. The adsorption process is defined asoccurring in three phases including an initial linear part, a second linear part and a third linear part. The first portion is the transport of $M G$ molecules from the bulk solution to the GO surface by diffusion through the boundary layer. The second part is the diffusion of the dye molecules from the surface of the GO adsorbent into the pores. The last part is the final equilibrium stage, where dye molecules are adsorbed onto the active sites on the internal pore surfaces, and the intra-particle diffusion plot starts slowing down due to the solute concentration declining ${ }^{29}$.

The surface adsorption mechanism was predominant within the $40 \mathrm{~min}$ contact time. There after, diffusion became the rate-limiting step. The intra-particle diffusion rate constant $\mathrm{k}_{\mathrm{p}}\left(\mathrm{mg} / \mathrm{g} \min ^{1 / 2}\right)$ was evaluated from the slope of the second linear part of the $q_{t}$ versus $t^{1 / 2}$ plot. The intra-particle diffusion model is used to elucidate the rate-limiting step of the adsorption process. The intercept of the plot indicates the boundary layer effect. If the linear plot goes through the origin,the rate-limiting step is only due to intra-particle diffusion. On the other hand, the larger the intercept obtained, the greater the contribution of surface sorption to the rate-limiting step $^{59}$.The value of $\mathrm{C}$ was high for $\mathrm{GO}$ resulting in more surface adsorption of the dye onto GO. Therefore, both mechanisms, surface adsorption and intra-particle diffusion, simultaneously cooperated in the adsorption behavior of the GO adsorbent.

\section{Adsorption isotherm}

The interaction between a liquid phase and an adsorbent is described by adsorption isotherms. These mathematical descriptions of equilibrium adsorption capacity in the adsorption process provide a reliable prediction of the adsorption parameters and a quantitative comparison of the adsorption behaviors of different adsorbent systems. The Langmuir and Freundlich models are the ones most frequently used to describe adsorption isotherms. The Langmuir model assumes that a monolayer of adsorbate covers a homogenous adsorbent surface. Adsorption takes place only at specific sites of the adsorbent, which is valid for monolayer sorption onto a surface, given by

$$
\frac{C_{e}}{q_{e}}=\frac{C_{e}}{q_{m}}+\frac{1}{q_{m} K_{L}}
$$

where $q_{m}$ is the maximum amount of dye absorbed per unit weight of adsorbent $(\mathrm{mg} / \mathrm{g})$ to form a complete monolayer covering the surface at the equilibrium state of dye concentrationc $\mathrm{e}_{\mathrm{e}}(\mathrm{mg} /$ $\mathrm{L}), \mathrm{q}_{\mathrm{e}}$ is the amount of dye adsorbed per unit weight of adsorbent at equilibrium, and $\mathrm{K}_{\mathrm{L}}$ is the Langmuir constant $(\mathrm{L} / \mathrm{mg})$ related to the surface affinity for the dye. The value of represents a practical limiting adsorption capacity when the surface is fully covered with dyeions. The values of and $K_{L}$ are calculated from the slope and intercept of the straight line plot of $\mathrm{C}_{\mathrm{e}} / \mathrm{q}_{\mathrm{e}}$ versus $\mathrm{C}_{\mathrm{e}}$.

The Freundlich adsorption isotherm is an equation that describes a heterogeneous surface. The mathematical form of the Freundlich adsorption isotherm is represented by Eq. (9).

$$
\log q_{e}=\log K_{F}+\frac{1}{n} \log C_{e}
$$

where, $\mathrm{K}_{\mathrm{F}}$ and $n$ are the Freundlich constantand the intensity of adsorption, respectively. The values of $K_{F}$ and $1 / n$ (between 0 and 1 ) can be obtained from a linear plotof $\log q_{e}$ versus $\log C_{e}$. 
Figure 11and Fig. 12 show fitting plots of Langmuir adsorption and Freundlich adsorption of MG using GO and BGP, respectively. The constant values obtained from the Langmuir and Freundlich adsorption isotherms and their correlation coefficients $\left(R^{2}\right)$ were calculated and are summarized in Table 3.

From the results, it can be concluded that for BGP adsorbent, the Freundlich isotherm $\left(R^{2}>\right.$ $0.97)$ fits the experimental results comparably to the Langmuir isotherm $\left(R^{2}>0.96\right)$. The slope $1 / n$ provides information about surface heterogeneity and surface affinity for the solute. If a higher value of $1 / n$ is obtained, it corresponds to greater heterogeneity of the adsorbent surface. Interestingly, for GO adsorbent, the Langmuir isotherm $\left(R^{2}>0.99\right)$ fit the experimental results better than the Freundlich isotherm $\left(R^{2}>0.93\right)$, indicating a homogenous adsorbent surface. The $M G$ ions were occupying only specific sites of the GO adsorbent, which is valid for monolayer sorption onto a surface. The maximum adsorption capacities were found to be 28.73 and $384.62 \mathrm{mg} / \mathrm{g}$ for BGP and GO, respectively. For comparison, the maximum adsorption capacity for this dye using other adsorbents is presented in Table 4. It is evident that the GO material has a high adsorption capacity for $M G$ removal from aqueous solution relative to the other carbon-based adsorbents.

\section{CONCLUSION}

Graphene oxide (GO) proved to be a highly effective adsorbent for malachite green (MG) removal from aqueous solution. Its $\mathrm{pH}_{\mathrm{pzc}}$ value was 4.1 , suggesting that the surface of $\mathrm{GO}$ should be predominantly positive at $\mathrm{pH}$ values lower than 4.1 and negative at $\mathrm{pH}$ values higher than 4.1. The surface charge density should increase or decrease as the $\mathrm{pH}$ value deviates more or less from the $\mathrm{pH}_{\mathrm{pzc}}$. The optimum conditions for removal of $M G$ from aqueous solution were a $300 \mathrm{mg} / \mathrm{L}$ initial concentration of MG with $0.02 \mathrm{mg}$ adsorbent at $\mathrm{pH}$ 5.1 , and thea dsorption state was completed within $40 \mathrm{~min}$. In addition, the adsorption capacity of GO decreased in the presence of higher ionic strength. This result corresponds to theoretical considerations defining that when the electrostatic forces between the adsorption surface and the adsorbateion sare attractive, an increase in ionic strength will decrease the adsorption capacity. The maximum adsorption capacity of GO for MG was $384.62 \mathrm{mg} / \mathrm{g}$, which is over 10 times higher than that of BGP $(28.73 \mathrm{mg} / \mathrm{g})$ according to their relevant functional groups. The adsorption process of $M G$ follows the pseudosecond-order kinetics model, indicating that the overall rate of MG uptake is controlled by external mass transfer at the initial stage of adsorption. In addition, the driving forces that control the adsorption rate later are attributable to intra-particle diffusion. Thermodynamic study of the adsorption process revealed that it was mainly an exothermic Spontaneous reaction. The adsorption isotherms fit well with the Langmuir and Freundlich models for GO and BGP, respectively. Therefore, the present study provides an excellent adsorbent for dye removal from aqueous solution. This adsorbent can also potentially be used for wastewater treatment.

\section{ACKNOWLEDGEMENTS}

This research was financially supported by Khon Kaen University, and the Ministry of Science and Technology, Bangkok, Thailand.

\section{REFERENCES}

1. Akar, E.; Altini_ik, A.; Seki, Y. Ecol. Eng. 2013, 52,19-27.

2. Podstawczyk, D.; Witek-Krowiak, A.; Chojnacka, K.; Sadowski, Z. Bioresour. Technol. 2014, http://dx.doi.org/10.1016/ j.biortech. 2014.01.015

3. Arellano-Cárdenas, S.; López-Cortez, S.;
Cornejo-Mazón, M.; Mares-Gutiérrez, J.C.Appl. Surf. Sci. 2013, 280,74-78.

4. Srivastava, S.; Sinha, R.; Roy, D. Aquat. Toxicol. 2004,66, 319-329.

5. Fallah, A.A.; Barani, A.Food Control. 2014, 40, 100-105.

6. Sudova, E.; Machova, J.; Svobodova, Z.; 
Vesely, T. VeterinarniMedicina.2007, 52, 527539.

7. Kalpana, P.; King, P. Asian J. Chem. 2014, 26, 75-81.

8. Chen, C.X.; Hou, Y.C.; Li, B.; Yi, W.Z. Asian J. Chem.2013, 25,3167-3171.

9. Cuiping, B.; Wensheng, X.; Dexin, F.; Mo, X.; Dong, G.; Zhongxue, G.; Yanshui, Z. Chem. Eng. J.2013, 215-216, 227-234.

10. Kant, S.; Pathania, D.; Singh, P.; Dhiman, P.; Kumar, A. Appl. Catal. B 2014,147,340-352.

11. Xu, R.; Jia, M.; Zhang, Y.; Li, F. MicroporousMesoporous Mater. 2012,149,111-118.

12. Lee, Y.C.; Kim, E.J.; Yang, J.W.; Shin, H.J. J. Hazard. Mater.2011, 192,62-70.

13. Kusvuran, E.; Gulnaz, O.; Samil, A.; Yildirim, O. J. Hazard. Mater.2011, 186,133-143.

14. Roosta, M.; Ghaedi, M.; Shokri, N.; Daneshfar, A.; Sahraei, R.; Asghari, A. Spectrochim. Acta, Part A. 2014, 118, 55-65.

15. Zhang, G.; Yi, L.; Deng, H.; Sun, P. J. Environ. Sci.2014, 26, 1203-1211.

16. Wang, L.; Zhang.J.; Zhao, R.; Li, C.; Li, Y.; Zhang, C. Desalination.2010, 254, 68-74.

17. Zhang, J.; Li, Y.; Zhang, C.; Jing, Y.J. Hazard. Mater.2008, 150, 774-782.

18. Hameed, B.H.; El-Khaiary, M.I. J. Hazard. Mater.2008, 159, 574-579.

19. Guo, Y.; Zhang, H.;Tao, N.;Liu, Y.;Qi, J.;Wang, Z.; Xu, H. Mater. Chem. Phys. 2003,82,107115.

20. Rahman, I.A.;Saad, B.; Shaidan, S.; Sya Rizal, E.S.Bioresour.Technol.2005, 96,1578-1583.

21. Bulut, E.; Özacar, M.;Ayhan^engil, I. MicroporousMesoporous Mater.2008, 115,234-246.

22. Han, R.;Wang, Y.;Sun, Q.;Wang, L.;Song, J.;He, X.;Dou, C. J. Hazard. Mater.2010,175,1056-1061.

23. Gong, R.;Feng, M.;Zhoa, J.;Cai, W.;Liu, L.Bioresour. Technol. 2009, 100, 975-978.

24. Gong, R.;Jin, Y.;Chen, F.;Chen, J.;Liu, Z.J. Hazard. Mater. B. 2006,137, 865-870.

25. Hameed, B.H.;El-Khaiary, M.I. J. Hazard. Mater.2008, 154, 237-244.

26. Hwa Beak, M.;ljagbemi, C.O.;Jin, O.S.;Su Kim, D.; J. Hazard.Mater.2010, 176, 820-828.

27. Ahmad, R.;Kumar, R.J. Environ. Manage.2010, 91, 1032-1038.
28. Mittal, A.J. Hazard. Mater. B.2006, 133, 196202.

29. Tang, H.; Zhou, W.;Zhang, L. J. Hazard. Mater. 2012, 209-210, 218-225.

30. Bekçi, Z.;Özveri, C.;Seki, Y.;Yurdakoç, K. J. Hazard. Mater.2005, 154, 254-261.

31. Samiey, B.;Toosi, A.R.; J. Hazard. Mater. 2010, 184, 739-745.

32. Zhang, L.; Zhang, H.;Guo, W.;Tian, Y. Appl. Clay Sci. 2014, 93-94, 85-93.

33. Rong, X.; Qiu, F.; Qin, J.;Yan, J,;Zhao, H.;Yang, D. J. Ind. Eng. Chem. 2014, http://dx.doi.org/ 10.1016/j.jiec.2013.12.083

34. Shamsizadeh, A.; Ghaedi, M.;Ansari, A.;Azizian, S.;Purkait, M.K.J. Mol. Liq.2014, 195, 121-128.

35. Sharma, Y.C. J. Chem. Eng. Data. 2011, 56, 478-484.

36. Tian, Y.;Liu, P.; Wang, X.;Lin, H. Chem. Eng. J. 2011, 171, 1263-1269.

37. Ahmad, M.A.;Alrozi, R. Chem. Eng. J. 2011, 171, 510-516.

38. Nethaji, S.;Sivasamy, A.;Thennarasu, G.; Saravanan, S. J. Hazard. Mater. 2010, 181, 271-280.

39. Santhi, T.;Manonmani, S.;Smitha, T. J. Hazard. Mater. 2010, 179, 178-186.

40. Méndez, A.;Fernández, F.;Gascó, G. Desalination. 2007, 206, 147-153.

41. Arriagada, D.C. J. Mol. Model. 2013, 19, 919930.

42. Li, Z.;Young, R.J.;Wang, R.;Yang, F.;Hao, L.;Jiao, W.;Liu, W. Polymer. 2013, 54, 58215829.

43. Xue, Y.;Liu, Y.;Lu, F.;Qu, J.;Chen, H.;Dai, L. J. Phys. Chem. Lett. 2010, 3, 1607-1612.

44. Madadrang, C.J.;Kim, H.Y.;Gao, G.;Wang, N.;Zhu, J.;Feng, H.;Gorring, M.;Kasner, M.L.;Hou, S. ACS Appl. Mater. Interfaces. 2012, 4, 1186-1193.

45. Yan, H.; Tao, X.; Yang, Z.; Li, K.; Yang, H.; Li, A.;Cheng, R. J. Hazard. Mater.2014, 268, 191-198.

46. Li, Y.;Du, Q.;Liu, T.;Peng, X.;Wang, J.;Sun, J.;Wang, Y.;Wu, S.;Wang, Z.;Xia, Y.;Xia, L. Chem. Eng. Res. Des. 2013, 91, 361-368.

47. Debnath, S.;Maity, A.;Pillay, K. J. Environ. Chem. Eng. 2014, 2, 260-272.

48. Chen, H.; Gao, B.; Li, H. J. Hazard. Mater. 2014, http://dx.doi.org/10.1016/ 
j.jhazmat.2014.03.063

49. Sun, L.;Fugetsu, B. Chem. Eng. J. 2014, 240, 565-573.

50. Yang, Z.; Ji, S.;Gao, W.; Zhang, C.; Ren, L.;Tjiu, W.W.; Zhang, Z.; Pan, J.;Liu, T. J. Colloid Interface Sci.2013, 408, 25-32.

51. Ramesha, G.K.;Vijaya Kumara, A.;Muralidhara, H.B.;Sampath, S. J. Colloid Interface Sci. 2011, 361, 270-277.

52. Nuengmatcha, p.;Mahachai, R.;Chanthai, S. Asian J. Chem.2014, 26 ,1321-1323.

53. Hummers, W.S.;Offeman, R.E. J. Am. Chem. Soc. 1958, 80, 1339.

54. Kongsri, S.;Janpradit, K.;Buapa, K.;
Techawongstien, S.; Chanthai, S.Chem. Eng. J 2013, 215-216,522-532.

55. Zhao, G.; Ren, X.; Gao, X.; Tan, X.; Li, J.; Chen, C.; Huang, Y.;Wang, X. Dalton Trans. 2011, 40, 10945-10952.

56. Saha, P.;Chowdhury, S.;Gupta, S.;Kumar, I. Chem. Eng. J. 2010, 165, 874-882.

57. Hadavifar, M.;Bahramifar, N.;Younesi, H.;Li, Q. Chem. Eng. J.2014, 237,217-228.

58. Zhang, H.;Tang, Y.;Liu, X.;Ke, Z.;Su, X.;Cai, D.;Wang, X.;Liu, Y.;Huang, Q.;Yu, Z. Desalination. 2011,274,97-104.

59. Vadivelan, V.;Kumar, K.V.J. Colloid Interface Sci.2005, 286, 90-100. 